\title{
Polycystic Ovary Syndrome and Cardiovascular Diseases: Still an Open Door
}

\author{
Marcus Vinicius Bolivar Malachias ${ }^{1,2}$ \\ Faculdade de Ciencias Medicas de Minas Gerais, ${ }^{1}$ Belo Horizonte, MG - Brazil \\ Instituto de Hipertensão Arterial, ${ }^{2}$ Belo Horizonte, MG - Brazil \\ Short Editorial related to the article: Women with Polycystic Ovarian Syndrome Exhibit Reduced Baroreflex Sensitivity That May Be Associated \\ with Increased Body Fat
}

This issue of the Brazilian Archives of Cardiology (ABC Cardiol) brings the article "Women with Polycystic Ovarian Syndrome Exhibit Reduced Baroreflex Sensitivity That May Be Associated with Increased Body Fat", by Philbois, SV et al., which draws attention to this clinical condition that is so prevalent in our country and its many aspects related to cardiometabolism, neuroregulation and cardiovascular risk. ${ }^{1}$

The Polycystic Ovary Syndrome (PCOS) is the most common endocrine disorder in women of reproductive age, ${ }^{2}$ with an estimated prevalence of 6 to $10 \%$ in this population. ${ }^{3}$ According to the Rotterdam criteria, PCOS is diagnosed in the presence of at least two of the three criteria: menstrual disorders or amenorrhea with chronic lack of ovulation, clinical and/or biochemical characteristics of hyperandrogenism and the presence of polycystic ovaries on ultrasonography after exclusion of other endocrine disorders. ${ }^{4}$ Overall, SOP has been considered a reproductive disorder; however, it also represents a significantly increased risk for cardiometabolic disorders. ${ }^{2}$ The impact on reproduction is predominant during the reproductive years, while cardiometabolic alterations become more important in the later stages of a woman's life. ${ }^{2}$

Women with PCOS are at increased risk of obesity, arterial hypertension, glucose intolerance, dyslipidemia and obstructive sleep apnea. ${ }^{5}$ Obesity is present in approximately $50 \%,{ }^{4}$ whereas insulin resistance occurs in $60 \%$ to $95 \%$ of them, ${ }^{6}$ leading to glucose intolerance in $31 \%$ to $35 \%{ }^{7}$ and type 2 diabetes mellitus in $7.5 \%$ to $20 \%^{8}$ of these women. However, dyslipidemia is the most common metabolic abnormality in PCOS, generally presenting with the phenotype exhibiting low levels of high-density lipoprotein (HDL) and high levels of triglycerides, consistent with insulin resistance, also presenting with increased insulin resistance and low-density lipoprotein (LDL) cholesterol levels. , $^{7}$

The prevalence of non-alcoholic fatty liver disease and obstructive sleep apnea are also high in women with PCOS. Even after controlling for body mass index (BMI), women with PCOS are still 30-fold more likely to have sleep-disordered breathing. ${ }^{9,10}$

\section{Keywords}

Polycystic Ovary Syndrome; Cardiovascular Diseases/ physiopatholog; Obesity/metabolism; Autonomic Nervous System/abnormalities; Baroreflex.

Mailing Address: Marcus Vinicius Bolivar Malachias •

Faculdade de Ciências Médicas de Minas Gerais - Alameda Ezequiel Dias,

275. CEP 30130-110, Centro, Belo Horizonte. MG - Brazil

E-mail: mbolivar@cardiol.br

DOI: $10.5935 / a b c .20190062$
Sub-clinical markers of cardiovascular disease, such as increased carotid artery intima-media thickness, ${ }^{11}$ increased calcification of the coronary arteries, ${ }^{12}$ and higher serum concentrations of C-reactive protein ${ }^{13}$ have also been associated with PCOS.

There is evidence that the autonomic nervous system (ANS) plays an important role in ovarian physiology regulation. ${ }^{14}$ It is estimated that increased sympathetic activity in women with PCOS may be associated with their hormonal and metabolic characteristics. ${ }^{15}$ Although autonomic dysfunction is considered a predictor of cardiovascular events and mortality, ${ }^{16}$ there is limited evidence of alterations in this pathophysiological parameter among women with PCOS.

A study showed that rats with estrogen-induced polycystic ovaries showed high uptake of norepinephrine, and a high degree of the neurotransmitter release with ovarian electrical stimulation. ${ }^{17}$ Yildirir et al. analyzed heart rate variation (HRV) in women with PCOS, demonstrating a significant increase in the low-frequency spectrum component and a decrease in the high-frequency component in relation to the control group. ${ }^{18}$ Tekin et al. showed a decrease in heart rate and blood pressure recovery after exertion in comparison to controls. ${ }^{19}$ Drag et al. demonstrated dysfunction of the sympathetic and parasympathetic components of ANS in women with PCOS using electromyography. ${ }^{20}$ The authors found no association between weight gain as measured by BMI and alterations in skin sympathetic response tests and R-R interval variation, parameter of the parasympathetic response, attributing to hyperandrogenism and insulin resistance the probable cause of the dysfunction. ${ }^{20}$ Using the HRV spectral analysis, the study by Philbois SV et al., published in this issue of $A B C$ Cardiol, found no alterations in autonomic cardiovascular control in women with PCOS. ${ }^{1}$ However, the authors correlated the decline in baroreflex sensitivity, an important measure of autonomic cardiovascular function, as well as the attenuation of HRV values, with the increase of body fat in women with PCOS. ${ }^{1}$

Although the results of the studies are conflicting, it can be concluded that insulin resistance, hyperandrogenism and obesity may result in autonomic dysfunction in PCOS..$^{1,17-21}$ This autonomic dysregulation is recognized as a factor of worse prognosis, ${ }^{16,22}$ in addition to the set of metabolic ${ }^{5-8}$ clinical, ${ }^{9,10}$ and structural alterations ${ }^{11-13}$ related to the syndrome when determining a higher cardiovascular risk. Despite all these demonstrations of subclinical dysfunction, there is still a lack of conclusive, long-term follow-up studies in these women, aiming to demonstrate definitive evidence of increased cardiovascular clinical outcomes associated with PCOS. ${ }^{23}$ 


\section{Short Editorial}

\section{References}

1. Philbois SV, Gastaldi AC, Facioli TP, Felix ACS, Reis RM, Fares TH, et al. Women with polycystic ovarian syndrome exhibit reduced baroreflex sensitivity that may be associated with increased body fat. Arq Bras Cardiol. 2019; 112(4):424-429.

2. Yau TT, Ng NY, Cheung LP, Ma RC Polycystic ovary syndrome: a common reproductive syndrome with long-term metabolic consequences. Hong Kong Med J. 2017;23(6):622-34.

3. Azziz R, Woods KS, Reyna R, Key TJ, Knochenhauer ES, Yildiz BO. The prevalence and features of the polycystic ovary syndrome in an unselected population. J Clin Endocrinol Metab. 2004;89(6):2745-9.

4. Azziz R, Carmina E, Dewailly D, Diamanti-Kandarakis E, Escobar-Morreale HF, Futterweit W, et al. The androgen excess and PCOS Society criteria for the polycystic ovary syndrome: the complete task force report. Fertil Steril. 2009;91(2):456-88.

5. Sartor BM, Dickey RP. Polycystic ovarian syndrome and the metabolic syndrome. Am J Med Sci. 2005;330(6):336-42.

6. Colilla S, Cox NJ, Ehrmann DA. Heritability of insulin secretion and insulin action in women with polycystic ovary syndrome and their first degree relatives. J Clin Endocrinol Metab. 2001;86(5):2027-31.

7. Legro RS, Gnatuk CL, Kunselman AR, Dunaif A. Changes in glucose tolerance over time in women with polycystic ovary syndrome: a controlled study. J Clin Endocrinol Metab. 2005;90(6):3236-42.

8. Boudreaux MY, Talbott EO, Kip KE, Brooks MM, Witchel SF. Risk of T2DM and impaired fasting glucose among PCOS subjects: results of an 8-year follow-up. Curr Diab Rep. 2006;6(1):77-83.

9. Vgontzas AN, Legro RS, Bixler EO, Grayev A, Kales A, Chrousos GP. Polycystic ovary syndrome is associated with obstructive sleep apnea and daytime sleepiness: role of insulin resistance. J Clin Endocrinol Metab. 2001;86(2):517-20.

10. Gopal M, Duntley S, Uhles M, Attarian H. The role of obesity in the increased prevalence of obstructive sleep apnea syndrome in patients with polycystic ovarian syndrome. Sleep Med. 2002;3(5):401-4.

11. Luque-Ramirez M, Mendieta-Azcona C, Alvarez-Blasco F, Escobar-Morreale HF. Androgen excess is associated with the increased carotid intima-media thickness observed in young women with polycystic ovary syndrome. Hum Reprod. 2007;22(12):3197-203.

12. Talbott EO, Zborowski JV, Rager JR, Boudreaux MY, Edmundowicz DA, Guzick DS. Evidence for an association between metabolic cardiovascular syndrome and coronary and aortic calcification among women with polycystic ovary syndrome. J Clin Endocrinol Metab. 2004;89(11):5454-61.

13. Boulman N, Levy Y, Leiba R, Shachar S, Linn R, Zinder O, et al. Increased $\mathrm{C}$-reactive protein levels in the polycystic ovary syndrome: a marker of cardiovascular disease. J Clin Endocrinol Metab. 2004;89(5):2160-5.

14. Aguado LI. Role of the central and peripheral nervous system in the ovarian function. J Microsc Res Tech. 2002;59(6):462-73.

15. Sverrisdottir YB, Mogren T, Kataoka J, Janson PO, Stener-Victorin E. Is polycystic ovary syndrome associated with high sympathetic nerve activity and size at birth? Am J Physiol Endocrinol Metab. 2008;294(3):E576-81.

16. Tsuji H, Larson MG, Venditti Jr FJ, Manders ES, Evans JC, Feldman CL, et al. Impact of reduced heart rate variability on risk for cardiac events. The Framingham Heart Study. Circulation. 1996;94(11):2850-5.

17. Lara HE, Ferruz JL, Luza S, Bustamante DA, Borges Y, Ojeda SR. Activation of ovarian sympathetic nerves in polycystic ovary syndrome. Endocrinology. 1993;133(6):2690-5.

18. Yildirir A, Aybar F, Kabakci G, Yarali H, Oto A. Heart rate variability in young women with polycystic ovary syndrome. Ann Noninvasive Electrocardiol. 2006;11(4):306-12.

19. Tekin G, Tekin A, Kilicarslan EB, Haydardedeoglu B, Katircibasi T, Kocum T, et al. Altered autonomic neural control of the cardiovascular system in patients with polycystic ovary syndrome. Int J Cardiol. 2008;130(1):49-55.

20. Dag ZO, Alpua M, Turkel Y, Isik Y Autonomic dysfunction in patients with polycystic ovary syndrome. Taiwan J Obstet Gynecol. 2015;54(4):381-4.

21. Di Domenico K, Wiltgen D, Nickel FJ, Magalhães JA, Moraes RS, Spritzer PM. Cardiac autonomic modulation in polycystic ovary syndrome: does the phenotype matter? Fertil Steril. 2013;99(1):286-92.

22. Thayer JF, Yamamoto SS, Brosschot JF. The relationship of autonomic imbalance, heart rate variability and cardiovascular disease risk factors. Int J Cardiol. 2010;141(2):122-31.

23. Goodman NF, Cobin RH, Futterweit W, Glueck JS, Legro RS, Carmina E, et al. American Association Of Clinical Endocrinologists, American College Of Endocrinology, and Androgen Excess and Pcos Society Disease State Clinical Review: guide to the best practices in the evaluation and treatment of Polycystic Ovary Syndrome - part 2. Endocr Pract. 2015;21(12):1415-26. 